\title{
Understanding the Influences Behind Parents' Asthma Decision-Making: A Qualitative Exploration of the Asthma Network of Parents with Children with Asthma
}

\author{
Pamela Srour-Alphonse - Biljana Cvetkovski • Elizabeth Azzi · \\ Cynthia Rand · Lynn H. M. Cheong · Vicky Kritikos · Sinthia Bosnic-Anticevich
}

Received: December 2, 2020 / Accepted: January 15, 2021 / Published online: February 10, 2021

(c) The Author(s) 2021

\begin{abstract}
Introduction: Interventions aimed at optimizing parents' ability to manage their children's asthma could be strengthened by better understanding the networks that influence these parents' choices when managing asthma. This study aimed to explore the asthma networks of parents of children with asthma-specifically to gain insights into whom parents select to be within their networks and why; how
\end{abstract}

P. Srour-Alphonse $(\bowtie) \cdot$ B. Cvetkovski · E. Azzi ·

V. Kritikos · S. Bosnic-Anticevich

Sydney Medical School, Faculty of Medicine and

Health, University of Sydney, Sydney, Australia

e-mail: psro4130@uni.sydney.edu.au

P. Srour-Alphonse · B. Cvetkovski · E. Azzi ·

V. Kritikos · S. Bosnic-Anticevich

Woolcock Institute of Medical Research, The

University of Sydney, Sydney, Australia

L. H. M. Cheong

Faculty of Health, University of Canberra, Canberra, Australia

S. Bosnic-Anticevich

Central Sydney Local Area Health District, Sydney, Australia

C. Rand

Pulmonary and Critical Care Medicine Department, John Hopkins University, Baltimore, MD, USA

V. Kritikos

Department of Respiratory Medicine, Royal Prince

Alfred Hospital, Sydney, NSW, Australia individuals within parents' networks influence the way in which they manage their children's asthma medications, and factors driving the development of these networks.

Methods: A qualitative research methodology utilizing semi-structured interviews with parents of children with asthma was employed to fulfil the objectives of this study.

Results: Twenty-six face-to-face interviews with parents of children with asthma were conducted, recorded, and transcribed. Transcriptions were independently coded for concepts and themes by the research team. Asthma medications was a dominant theme identified, and revealed that parents actively sought advice and support from a series of complex and multidimensional relationships with people and resources in their health network. These not only included health care professionals (HCPs) but also personal connections, lay individuals, and resources. The composition and development of these asthma networks occurred over time and were determined by several key factors: satisfaction with their HCP provider; need for information; convenience; trust and support; self-confidence in management; and parents' perceptions of their children's asthma severity.

Conclusions: By exploring parents' asthma network, this study uncovers the complex relationship between HCPs, family and friends of parents of children with asthma, and provides new insight into the intimate and parallel 
influence they have on parent's decision-making.

Keywords: Asthma; Influence; Medications; Networks; Pediatric; Parents; Self-management

\section{Key summary points}

Why carry out this study?

Interventions aimed at optimizing parent's ability to manage their child's asthma could be strengthened by better understanding the networks that influence these parents' choices when managing asthma.

There is a need to explore the asthma networks of parents of children with asthma-specifically to gain insights into whom parents select to be within their networks and why; how individuals within parent's networks influence the way in which they manage their child's asthma medications, and factors driving the development of these networks.

\section{What was learned from the study?}

It adds to our depth of understanding relating to the sources of information/support within which parents of children with asthma engage, and for the first time articulates the relative importance and influence that parents place on different sources of health information.

Emphasizes the major gap in our guidelines, which despite their evolution, continue to be framed in a biomedical model of health care and fail to address the needs of parents.

Supports the need for a collaborative approach to the management of pediatric asthma, which involve medical and nonmedical individuals.
Highlights the need to develop pediatricspecific guidelines for asthma management, which foster a 'community' approach to management.

\section{DIGITAL FEATURES}

This article is published with digital features, including a summary slide, to facilitate understanding of the article. To view digital features for this article go to https://doi.org/10.6084/ m9.figshare. 13574507

\section{INTRODUCTION}

Asthma is one of the most common chronic conditions in the Australian pediatric population, affecting up to $20.8 \%$ of children at some stage in their childhood, with $11.3 \%$ of children having a current asthma diagnosis $[1,2]$. The burden of pediatric asthma is significant; high rates of unscheduled emergency department visits and hospitalizations, sleep disturbances in one-third of children, $60 \%$ reporting absenteeism from school, study or other activities [1-3], and considerable extended burden for the whole family through for example missed days of work, sleep deprivation, and anxiety $[4,5]$.

Parents of children with asthma play a key role in their asthma management, however current data suggest that parents are falling short in their abilities to optimally manage the condition [6]. Despite receiving education, in some cases parents still identify a need for more education and information about medication use from professionals $[7,8]$, demonstrating significant gaps in medication knowledge [9-11], as well as skills in adherence [12-14] and inhaler technique [15-17]. This need for information has continued for years, despite parents having access to healthcare professionals (HCPs) [8]. Parents also have a large circle of non-medical individuals/resources to whom they also turn to [18]. Most importantly, poorly managed asthma has important consequences for the family, health care systems, and the child. A lack of parents' knowledge and skills has ramifications on children's understanding of asthma, 
especially as children grow older and learn to self-manage their condition, and therefore this should be addressed. It is important that children start with a solid knowledge base.

Research has established that parents establish their own sources of health information, i.e., their own "health networks" that relate to their children's asthma medication management [18]. These networks include professional connections ( $44 \%$ of networks), i.e., their health care professionals (HCP)(such as general practitioners (GPs), respiratory specialists, pediatricians, pharmacists, hospital staff), personal connections (such as spouses, family and friends; $42 \%$ of networks), and impersonal connections such as lay individuals (such as school staff, work colleagues; $14 \%$ of networks) and resources (such as information resources obtained off the internet or patient support groups including asthma organizations). Exploration of these networks highlights that the parent's health networks are large, complex, and variable with the influence of HCPs being just as significant as the influence of non-HCPs on the management of their children's asthma medications [18]. The asthma networks of participants ranged from two to ten connections, with an average number of five. The most commonly nominated connection was with general practitioners (GPs) followed by family members and the internet. When parents were asked about how influential these connections in their health networks were, professional connections represented 53\%, personal connections 36\%, and impersonal connections $11 \%$ [18]. What this research does not tell us is that although parents have specific preferences for particular health connections, it remains unknown what their role in asthma medication management is, on what basis they selected specific individuals for health advice, and how they may impact the strategies parents employ in the management of their children's asthma medications. We hypothesize that different individuals/resources in parents' networks have different roles within their influence of decisions and choices parents make in management, and this may not be related to the importance parents place on each. Understanding these connections and their importance to parents is critical to our understanding of parent perspectives and decision-making. This will enable HCPs and the community to better support the optimal management of their children's asthma.

The overall aim of this study is to gain a deeper understanding of the asthma networks of parents; specifically, to gain insights into:

i) The role of individuals/resources within parent's asthma networks, their level of importance to parents, and how they influence the way in which parents manage their children's asthma medications, and

ii) Factors driving the development of these networks.

\section{METHODS}

\section{Study Design}

The study was conducted between January and May of 2017. It was based on novel empirical data describing the composition of asthma networks parents established within the context of managing their children's asthma medicines [18]. Building on this research, this study adopted a qualitative approach to drive an indepth, qualitative exploration of the connections, relationships, and influences in these asthma networks. This project was approved by the University of Sydney Human Research Ethics Committee (Project No: 2015/762). Methods were performed in accordance with consolidated criteria for reporting qualitative research regulations and guidelines [56].

\section{Setting and Sampling Frame}

The sampling frame included parents of children with asthma who had previously participated in research in this line of inquiry [18]. These parents were contacted as they had previously expressed an interest to be part of future studies and were screened for eligibility. Selection was based on a set of inclusion criteria (Table 1). Once eligibility was established, all parents provided written consent prior to participation. 
Table 1 Criteria for recruitment of participants for the study

\begin{tabular}{|c|c|}
\hline Inclusion criteria & Exclusion criteria \\
\hline $\begin{array}{l}\text { 1. Parents with a child aged } \\
\text { between } 4 \text { and } 18 \text { years }\end{array}$ & $\begin{array}{l}\text { 1. Parents not fluent in } \\
\text { English }\end{array}$ \\
\hline $\begin{array}{l}\text { 2. Child has a diagnosis of } \\
\text { asthma (self-reported) }\end{array}$ & $\begin{array}{l}\text { 2. Parents of children who } \\
\text { had any other comorbid } \\
\text { chronic illness along with } \\
\text { asthma (with the } \\
\text { exclusion of allergic } \\
\text { rhinitis, eczema, and } \\
\text { generalized allergic } \\
\text { disorder) }\end{array}$ \\
\hline $\begin{array}{l}\text { 3. Child has used an asthma } \\
\text { preventer medication for } \\
\text { at least } 3 \text { months in the } \\
\text { past } 12 \text { months }\end{array}$ & \\
\hline $\begin{array}{l}\text { 4. Previously participated in } \\
\text { a research line of inquiry } \\
\text { prior to the } \\
\text { commencement of this } \\
\text { study }\end{array}$ & \\
\hline
\end{tabular}

\section{Data Collection}

Data collection occurred in two parts and by one researcher (PSA):

i. Participant demographics and baseline data Participant demographic and baseline data were collected and included: age, gender, asthma history, highest level of education, and occupation. The child's level of impairment due to asthma was assessed using the functional severity questionnaire (FSQ) [18].

ii. Semi-structured interview

Prior to the commencement of this study, participants had identified individuals and resources with whom/which they engaged around their child's asthma medicines [18]. These individuals and resources identified in parent's asthma networks and were referred to as 'alters' [18]. For this study, participants were required to reflect on the 'alters' that they had previously identified within their asthma network.

A semi-structured interview guide (Table 2) was developed based on empirical evidence $[18,20-23]$, the theory of self-management and the theory of pediatric medication autonomy [24-35]. The interviews were recorded on digital media devices and transcribed verbatim.

\section{Data Analysis}

Participant Demographics and Baseline Data Descriptive statistics were used to summarize participant demographic and baseline data. The FSQ [19] consists of six questions with five questions utilizing 5-point Likert scales and one question requiring a 'yes/no' response where 4 points were given for yes and 0 points for no. The raw sum of the six question scores were then calculated and a severity score of low, mild, moderate, or severe was then allocated.

\section{Semi-Structured Interview}

Transcribed interviews were reviewed to identify descriptive and contextual information. Deductive and inductive approaches were used to analyze content, identify categories, and arrange them into themes [47]. A deductive approach was used to explore a participant's selection of individuals and resources in their children's asthma medication management, an investigation of their role, relative importance to participants, their impact on their child's asthma medications, and finally on other relations within their networks. An inductive approach was used to identify concepts and themes associated with the development of asthma networks.

Data collection and analysis occurred concurrently, enabling further exploration of emerging themes. To ensure reliability and validity, data were independently reviewed (PSA, EA, SBA, LC, and BC) to develop inductive and deductive codes. These included any issues, topics, or ideas discussed and raised by participants. Deductive codes were developed from topics in the interview guide and research literature, while inductive codes were developed 
Table 2 Semi-structured interview guide

\begin{tabular}{|c|c|c|c|}
\hline Topics & Primary questions & Secondary questions & Clarification \\
\hline \multicolumn{4}{|c|}{$\begin{array}{l}\text { In this interview, we are going to discuss all the individual and resources that you mentioned were in your asthma networks. } \\
\text { These individuals and resources will be referred to as 'alters'. For each alter you mentioned: }\end{array}$} \\
\hline $\begin{array}{l}\text { Role in } \\
\text { medication } \\
\text { management }\end{array}$ & $\begin{array}{l}\text { How is "alter } \mathrm{x}^{*}{ }^{*} \text { involved in your } \\
\text { child's asthma medications? } \\
\text { What is the role of "alter } \mathrm{x} \text { " when it } \\
\text { comes to managing your children's } \\
\text { medications? }\end{array}$ & $\begin{array}{l}\text { Why have you chosen "alter } x^{\text {}} \\
\text { to help you with your child's } \\
\text { asthma medications? } \\
\text { Have your child's asthma a } \\
\text { medication needs been met? }\end{array}$ & $\begin{array}{l}\text { How has "alter } \mathrm{x} \text { " helped you } \\
\text { with your child's asthma } \\
\text { medications? }\end{array}$ \\
\hline \multirow[t]{2}{*}{ Influence } & $\begin{array}{l}\text { How has "alter } \mathrm{x} \text { " influenced the } \\
\text { management of your child's asthma } \\
\text { medications? }\end{array}$ & $\begin{array}{l}\text { How has "alter } x \text { " impacted the } \\
\text { management strategies that } \\
\text { you use? }\end{array}$ & $\begin{array}{l}\text { Have you had any positive/ } \\
\text { negative interactions with } \\
\text { "alter } x \text { "? }\end{array}$ \\
\hline & $\begin{array}{l}\text { Have you made any changes to your } \\
\text { child's asthma medications after } \\
\text { interacting with "alter } x \text { "? }\end{array}$ & & $\begin{array}{l}\text { Have they changed any of your } \\
\text { habits when it comes to your } \\
\text { children's medications? }\end{array}$ \\
\hline \multirow[t]{2}{*}{$\begin{array}{l}\text { Connection } \\
\text { development }\end{array}$} & $\begin{array}{l}\text { How did this relationship with "alter } \\
\text { x develop? }\end{array}$ & $\begin{array}{l}\text { Why did you start interacting } \\
\text { with/using "alter x"? }\end{array}$ & $\begin{array}{l}\text { How long have you known } \\
\text { "alter } x \text { "? }\end{array}$ \\
\hline & $\begin{array}{l}\text { Can you describe the history and } \\
\text { frequency of interaction with "alter } \\
x \text { " in your network diagram? }\end{array}$ & $\begin{array}{l}\text { Did any alter play a bigger role } \\
\text { than others in your child's } \\
\text { asthma care? }\end{array}$ & \\
\hline
\end{tabular}

Alter $\mathrm{x}$ was stated as an 'individual'/resource noted previously by the participant

through analytic reading of the data. Regular meetings were held to then critically compare and discuss findings, reaching consensus on recurrent codes and themes. The software package NVivo 9 (QSR International, Melbourne, Australia) was used for data management, content analysis, as well as modeling of categories and sub-categories. Themes that consistently emerged are reported in the results below. Descriptive statistics were used to summarize participant demographic and baseline data.

\section{RESULTS}

\section{Participant Characteristics}

A total of 26 parents of children with asthma participated in this study. The average time for each interview was $25 \mathrm{~min}$, ranging from 15 to $40 \mathrm{~min}$.

Participant demographics and baseline data are summarized in Table 3. Mothers represented $100 \%$ of participants $(n=26)$. The mean age of participants was $42 \pm 7$ (mean \pm SD) and $10 \pm 4$ (mean \pm SD) for the participant's children. In this study, 46\% (12/26) participants had asthma themselves. When looking at participant's children, $77 \%$ were aged between 4 and 12 years and $23 \%$ between the ages of 12 and 18 . Of these children, $62 \%$ were female and $73 \%$ had mild asthma as evaluated by the Functional Severity Questionnaire (FSQ) [47]. Reporting of past experience with health care utilization indicated that all children $(26 / 26$, $100 \%$ ) had been hospitalized at least once for their asthma in the past; $69 \%(18 / 26)$ in the last 2 years and $38 \%(10 / 26)$ in the previous 12 months. Overall, 58\% (15/26) of children 
Table 3 Participant demographics and baseline data $(n=26)$

Category $n(\%)$

Age range, years

Participant

18-29

30-49

50 or more

Participant's children

$$
\begin{aligned}
& 4-10 \\
& 11-14 \\
& 15-18
\end{aligned}
$$

Gender

Participant

Female

Male

Participant's children

$$
\text { Female }
$$

Male

$16(62)$

Asthma status

Asthmatic

$12(46)$

Non-asthmatic

$14(54)$

Highest level of education

Year 11 or below (includes Certificate I/II)

Higher school education

Certificate III/IV

Diploma

Bachelor degree

Postgraduate degree

Children's asthma functional severity

Low (score 0-4)

Mild (score 5-8)

Moderate (score 9-14)

$1(4)$

$1(0)$

Severe (score 15-22)
Table 3 continued

\begin{tabular}{ll}
\hline Category & $\boldsymbol{n}(\%)$ \\
\hline Ever been hospitalised & $26(100)$ \\
Hospitalised in past 2 years & $18(69)$ \\
Hospitalised in past year & $10(38)$
\end{tabular}

Missed school days due to asthma in past year

0

$11(42)$

$>1$

$15(58)$

How often children had asthma symptoms in past year

No symptoms

Less than monthly

$17(65)$

At least monthly

Other family members with asthma

Yes

Ethnicity

Anglo Australian

Arab Australian

Italian Australian

Sri Lankan Australian

Indian Australian

$1(4)$

Greek Australian

$2(7)$

Egyptian Australian

$1(4)$

Macedonian Australian

$1(4)$

Maltese Australian

$2(8)$

had taken at least 1 day off from school due to asthma in the previous 12 months; $42 \%(11 / 26)$ had taken no days off due to asthma. Participants reported that over the previous 12 months, two children $(2 / 26,8 \%)$ did not experienced any symptoms, 65\% (17/26) experienced symptoms less than monthly, whereas $27 \%(7 / 26)$ had experienced symptoms more than once per month.

Rate of children's hospitalisation due to asthma 


\section{The Perceived Role of Individuals/ Resources Within Parent's Asthma Networks and How They Influence the Way in Which Parents Manage Their Child's Asthma Medications}

Overall, participants reported wide differences in the nature and level of influence/importance of the different individual/resources identified. Exploration of these networks uncovered a series of complex and multidimensional relationships, and highlighted that some relationships/ individuals truly influenced the decisions made by participants, others filled a gap in knowledge and understanding, others were convenient relationships, and some connections were unrelated to the child's asthma but provided support to parent's continual needs.

The specific roles and subsequent influences of individuals/resources are presented under the four categories: healthcare professional (HCP) connections, personal connections, lay individuals, and resources. These relationships and influences are discussed in detail below with examples from participant responses in Table 4.

\section{HCP Connections}

HCP connections included general practitioners (GPs), specialists (respiratory and pediatric), pharmacists, and hospital staff.

Participants considered the GP to be "officially in charge" of their child's asthma and GPs were reported to serve a wide range of roles (18/ $26,72 \%)$. These included the diagnosis of asthma; including physical examinations (inspections of chest and upper airways); being the first point of call in recognizing and confirming any respiratory symptoms and re-confirming a hospital diagnosis of asthma post discharge if the hospital was the first point of call. There was complexity reported around the 'diagnosis' role, as participants reported that GPs were hesitant to confirm a diagnosis of asthma at a young age (under 5 years of age). A diagnosis was often only confirmed by the GP after a hospital visit when symptoms had exacerbated during an acute attack or a flare up of symptoms, resulting in parents often feeling "frustrated" $(11 / 18,61 \%$ of parents whose primary provider was their GP).

GP's were also described as actively involved in the prescribing of asthma medications, commonly described as taking a "trial and error" approach, to determine the most suitable medication for their child. Some participants specifically noted that their GP tended not to provide information about all possible medication side effects or the reasons for prescribing a particular medication. Specifically, GPs were reported to not provide day-to-day management advice, which participants expected would be discussed.

A very small number $(5 / 18,19 \%)$ of parents reported that their GPs supplied a written asthma self-management plan and conducted inhaler technique assessments and training. The GP also left participants with many unanswered questions, and concern about treatment options and the medications their children had been prescribed. Participants reported that this impacted their willingness to give their children medication and made them more cautionary in taking on the management suggestions of the GP. Six participants expressed that they only see the GP now for prescription renewal.

Specialists who were seen by a proportion $(12 / 26,46 \%)$ of participants (were seen to deliver "specialized care" as "experts in the field". They were "respected" by all participants who were in their care and described their advice as "valued". This advice made participants feel "confident" that the medication prescribed and management recommended were the most appropriate for their child. They were involved in the diagnosis of asthma, especially when participants did not receive a definitive diagnosis from their GP. Specialist diagnosis of asthma involved monitoring of respiratory symptoms, lung function tests, and trialing of asthma medications for symptom relief. Specialists were reported to consider the role of allergy in asthma and initiated immunotherapy if required. They were also involved in medication management, which entailed medication dose adjustments, providing written asthma self-management plans, trialing different asthma medications, adjustment of medications 
Table 4 Quotes supporting the perceived role of individuals/resources within parent's asthma networks and how they influence the way in which parents manage their child's asthma medications

\begin{tabular}{|c|c|}
\hline Theme & Quote \\
\hline
\end{tabular}

connections

Practitioner

Specialist

Pharmacist

Personal

connections

Lay Individuals
'He had his first bad asthma attack and that's when we were told he was an asthmatic. He had to be hospitalized for our GP to finally realize he had asthma! We were petrified and annoyed that that was what it took for him to make up his mind!' (Participant 5)

"He [GP] didn't recommend anything except that [reliever medication]. He said. This is the best thing for him and it's working for him. We continue on and didn't explain to me why. He didn't even give me anything to make his immune system strong or to prevent this [asthma attack] happening again -I was surprised.' (Participant 12)

"Basically [saw a GP] whenever I needed a script. Everything else is taken care of by the specialist." (Participant 23)

"Since we started seeing the specialist, it's the specialist whose view that I've paid most attention to. I refer to his view, and then the GP. Because I feel that he's got more specialist knowledge of asthma treatment in children, or asthma treatment full stop, but certainly in children." (Participant 10)

Hospital Staff 'I had to go buy a machine because that's what they used in the hospital. They said if this is happening again [asthma attack] this is the best way to do it. They showed me what to do and now I every time I see my daughter even slightly short of breath I put the nebulizer for her and it is completely fine." (Participant 12)

"We just go in there [community pharmacy] and fill our scripts and go" (Participant 16)

"I've already got the information by the time I get to the pharmacist" (Participant 1)

"If she is in a state where at the moment she is experiencing symptoms, I may ask the person looking after her to keep an ear out and if they do notice her coughing to remind her to take some medication" (Participant 3)

'I think the more you learn about other people's asthma, the more you understand what to do if something does go wrong. Or at least have someone to call for advice if you get told, oh, your daughter's asthma is severe now and you need to take this and this and every day-someone to cry to or stress out to, or whatever." (Participant 14)

"I didn't trust my GP on it. After having talked to other mothers about it, and finding out that there is asthma advice, and asthma advice, I just thought I want to get to the bottom of it. We went to a pediatrician one of the mothers recommended, who we still see. He was horrified about the amount of Ventolin that he was on." (Participant 10)

'Well, you just listen to what they would do or what they've been told and then you think, okay, maybe I should go to the doctor now because it sounds like a similar situation and that's a pretty good idea to ask them about, and you go to the doctor and ask" (Participant 7)

"No, they (school staff) just ask for the action plan, they're not really involved, as long as she can manage by herself they don't have a lot to deal with it." (Participant 6) 
Table 4 continued

\begin{tabular}{ll}
\hline Theme & Quote \\
\hline Resources & "Now if I hear anything about anything, I go to Google. I'll type whatever question comes to \\
& my head, whatever that is for anything. About medication, about anything, I just Google \\
& it to see what is this. The more you ask the more information you get, and the more you \\
can stem together" (Participant 12)
\end{tabular}

according to different seasons, and weaning of regular medications if possible.

Hospital staff, such as medical practitioners and nurses, provided emergency asthma care during acute exacerbations which participants viewed as "lifesaving" $(11 / 26,46 \%)$. Their influence, however, went far beyond the acute management of the child's asthma. In these circumstances, hospital staff were highly influential, and participants reported that they played a role in the way they administered asthma medication to their children post hospital admission, i.e., participants modeled their medication administration behaviors on what they saw in the hospital under emergency circumstances for all future medication administration.

When mentioned by participants (14/26, $54 \%$ ), for all, the pharmacist played a fundamental role in the supply of medications. Beyond this, there was a dichotomy of roles described. A majority of participants (10/14, $71 \%$ ) reported limited potential of the pharmacist to contribute towards their child's medicine management and only turned to the pharmacists for medication supply having infrequent interactions with them. They reported that information about medications, inhaler technique training, and management suggestions were covered by their GP or specialist and did not require any further support. Further participants reported being uninterested in the standard questions and common advice that was provided. For a smaller minority (4/14, $29 \%)$, roles reported included medication information and advice, inhaler technique education, and assisting with prescription issues (dealing with incorrect dosages, confirming directions, providing emergency medications when doctors could not be seen). Emotional support and referral to other HCPs were also reported. Some participants described a pharmacist as "dependable", making them feel "confident" in the way they administered medications to their children and helping to understand the importance of medications and "taking the orange inhaler [reliever] everyday".

\section{Personal Connections}

Personal connections included family $(16 / 26$, $62 \%)$ and friends $(10 / 26,38 \%)$, featured throughout participant asthma networks. Participants frequently encountered on-going challenges in the management of their children's asthma medications and while they would interact with HCPs occasionally to rectify these issues when in need of a professional opinion, they would interact with family and friends on a more regular basis, as they lived and socialized with most of these individuals on a daily basis.

For family $(9 / 26,35 \%)$ and friends $(5 / 26$, $19 \%)$ who did not have asthma themselves, they were not reported to be influential in the participants decision-making around their child's asthma medications, however, they were still reported to play an important role in their network. They were involved in physically assisting the participant with the practical aspects of their child's asthma care. During events such an asthma attack or symptom exacerbation, participants turned to these individuals who could assist them in an emergency, watch over their children, and provide continuing assistance with daily life tasks. This included monitoring their child's asthma for acute symptoms when in their care, identifying any increase in asthma symptoms that they may 
Table 5 Quotes supporting the factors driving the development of asthma networks

\begin{tabular}{ll}
\hline Theme & Quote \\
\hline Level of satisfaction with their & "So, I'll go to the specialist whenever I actually feel uncomfortable with what the GP \\
primary HCP providers & has told me-or he can't convince me with whatever information he is giving me" \\
& (Participant 17)
\end{tabular}

"The doctor talked without any pause to allow me to ask questions. They were not interested to focus on listening or pay close attention to (the) questions asked, (and) when I was finally able to ask, he was always cutting me (off) while I was in the middle of asking or explaining my concerns. I just got so frustrated.' (Participant 23)

"Even like doctors sometimes they misjudge, one doctor gave him the Redipred for three days which he didn't need to take and at the end he needed antibiotics for a bacterial infection, I wasn't very happy or pleased. He didn't even explain why he needed it!" (Participant 20)

'See he [GP] didn't even tell me to use the spacer at the beginning so there was a little kid trying to take a puffer because when I was a kid it wasn't an aerosol it was the twisty powder so I didn't know about the spacer thing. It wasn't until I decided to go see the pharmacist and ask her what to do did that she told me to get a spacer."

(Participant 5)

"My mum has been my greatest influence, she actually taught me more than my doctor. Mum always said to me when you take the Ventolin, you breathe in and you leave it in as much as you can, then you breathe out. I mentioned that to the doctor, and the doctor goes that's rubbish and just dismissed it, didn't explain why! or what the correct way was! But when I mentioned it to the nurse who taught us the anaphylactic course, and I mentioned this is what Mum said, the doctor said it was rubbish, she said no, she's right. Listen to your mum." (Participant 23)

Trust and Support

In general, ladies I know, their kids have asthma and we talk to each other about it. I tell them that I'm using the Ventolin on my kids and we start borrowing it from each other like it's a toy or something if their kids are sick. Without bothering to go to the doctor because we know it's worked for our own kids and they trust us. They start using it on their kids!' (Participant 12)

'With her [friend] I've talked about it a lot; she's seen the worst-case scenario, and I've known her all my life, so I feel comfortable talking with her. So, she's had Davidworst-case scenario-and I know that I can trust what she has to say and she's provided me with great advice in the past that's worked. Also referred me to a great specialist! She was also the first person that I knew who also had a child with asthma." (Participant 7)

"Of course, they [GP] helped me and I will never go to another doctor again because he introduced me to all the medication and this worked for me and my son is very well. He also answers any questions I have whenever he can at any time of the day, he is always supportive?. (Participant 12) 
Table 5 continued

\begin{tabular}{|c|c|}
\hline Theme & Quote \\
\hline \multirow[t]{2}{*}{ The need for more information } & $\begin{array}{l}\text { 'Like I want more information about how managing it is going to help long term... } \\
\text { like sport she can run and it doesn't really affect her but I don't know if the weathers } \\
\text { going to affect her all the time, if she's going to need to have this on her always, if } \\
\text { she's out of it.... The doctor didn't really go into the details... and I feel a little lost.' } \\
\text { (Participant 6) }\end{array}$ \\
\hline & $\begin{array}{l}\text { "I didn't know how to use a spacer. The doctor told me, obviously, but I had forgotten } \\
\text { and you just want help from other people as well on a regular basis to feel more } \\
\text { confident. So, I would talk to the other parents and they'll be like, oh, do this and do } \\
\text { that, and we sort of put information together, so their view, the doctor's view, my view } \\
\text { and I would feel better about the situation." (Participant 7) }\end{array}$ \\
\hline $\begin{array}{l}\text { Perception of their child's asthma } \\
\text { severity }\end{array}$ & $\begin{array}{l}\text { "Well our family GP, I don't need to see her that often unless we need a script. I never } \\
\text { actually went to see any specialist because he wasn't really that bad. I had a friend, } \\
\text { her son, who was probably worse and he needed to see a specialist, so I didn't think } \\
\text { my son was in that category". (Participant 9) }\end{array}$ \\
\hline Convenience & $\begin{array}{l}\text { 'No offence to any doctors with all my respect. If you go to the doctor the doctor has a } \\
\text { time limit. He doesn't have time to sit down with you and explain everything to you. } \\
\text { He will give you the medicine and say see you later, because there's people waiting to } \\
\text { see him. So, these days I won't ask anymore-I don't even-I just Google whatever I } \\
\text { want and read about it. They tell you all the information, it's very clear and quick to } \\
\text { get too.' (Participant 12) }\end{array}$ \\
\hline
\end{tabular}

have overlooked themselves, and aiding with the administration of medications.

Having family and friends who were always available in all situations was invaluable to participants ongoing management of their children's asthma. They also provided participants with emotional support for feelings of anxiety and fear, which were a result of caring for a child with asthma. The "support" of family and friends was described with regard to their influence in triggering the participant to seek professional assistance, especially when their child's asthma symptoms worsened. More importantly, family and friends were found to influence participants' choices of HCPs. Often participants' selection of HCPs was influenced by family and friends' recommendations.

When it came to family $(7 / 26,27 \%)$ and friends $(5 / 26,19 \%)$ who either had asthma themselves or a child with asthma, their role was similar to that of other friends (described above), however also related to the sharing of personal lived experiences, stories, and insights. Spouses who had asthma themselves were identified by participants to be role models for their children when it came to administering medications on their own without assistance from parents. Participants reported that it was helpful to turn to these individuals who had similar experiences as they provided realistic advice and valued this sharing as they did not believe they received this from HCPs. They also provided practical advice regarding medication use, such as advice on inhaler device use and technique, as well as medication dosages. Their high level of influence on participant's medication management was conveyed in the way they often relayed management-related information that they had heard from family and friends back to HCPs. They also compared the management advice they had received from their HCPs between each other and took on 
each other's management advice, even if it contradicted what they were told by their own HCPs.

\section{Lay Individuals}

Individuals such as school staff and work colleagues were labeled as lay connections (14/26, $54 \%$ ) in participants asthma networks. The role of school staff was to administer asthma medication following an individualized written asthma self-management plan, especially when a child was experiencing acute asthma symptoms. They were also to inform participants of any symptoms their child has experienced while at school. Outside of that, participants did not perceive them to be influential in any way when it came to managing any aspect of their children's asthma.

When it came participant's work colleagues, they played a supportive role for participants. That is, they provided participants with a place to share their experiences, feelings, and emotions. If they had asthma themselves, they shared their stories and insights, however, they reported that this had no impact on their management strategies or decisions when it came to their child's asthma management.

\section{Resources}

In addition to professional and personal connections, participants also reported to turn to other resources for additional asthma medication-related information such as the Internet and pamphlets.

Participants $(15 / 26,58 \%)$ in this study frequently reported turning to the Internet for health information both prior to and after their interactions with HCPs. Participants used this resource to find practical information regarding their children's medications, their administration, side effects, and to find new and upcoming treatment strategies, particularly when their children experienced increased asthma symptoms. Participants reported feeling empowered as a result of access to quick health information. They reported that this influenced their decision-making independently from HCPs in regard to which medications their child should be on, adherence to medications, and when to initiate or cease medications.

\section{Factors Driving the Development of Asthma Networks}

Inductive analysis of the data identified that the development of these asthma networks occurred over time and was driven by six factors: the level of satisfaction with their primary HCP provider; the need for different information; convenience; trust and support; self-confidence in management; and participant perception of their child's asthma severity. These factors are discussed below and supported by quotes from participants in Table 5.

\section{Level of Satisfaction with Their Primary HCP Providers}

All participants utilized general practitioners (GPs), often being accessed when their child first started experiencing symptoms of asthma. While GPs were considered highly influential, participants had their own individual expectations of their GP. A large proportion of participants $(12 / 18,67 \%)$ expressed dissatisfaction with their GP, articulating that their needs were not being met.

Some participants $(10 / 18,55 \%)$ reported that their GP had poor professional communication. They were not given a chance to ask questions, and if they managed to do so, they were interrupted. Others reported their GP failed to answer their questions, and instead of addressing their concerns, their GP proceeded to ask other questions important to them.

Other participants reported that their GP provided inadequate information in relation to at least some aspects of their child's asthma management and treatment or highlighted the poor quality of information provided. While participants did not recognize all the gaps and found it difficult to pinpoint and express their exact needs, they expected to be provided with more detailed explanations on medication side effects (long-term side effects), prognosis of their child's asthma (if the child will "grow out of it"), potential complications of living with asthma, health management strategies in case 
of worsening asthma, and any new upcoming treatments (research in the area). Especially in cases where they found themselves in an unfamiliar or critical situation that they did not how to deal with, e.g., being unprepared to recognize or respond to an exacerbation of asthma.

Further, participants highlighted that they wanted advice about how to manage their child's asthma on a day-to-day basis. In terms of medicine administration, several participants reported that they were given a demonstration on proper inhaler technique on one occasion, without reinforcement or assessment over time. The majority of participants reported that their child's inhaler technique was never assessed. Few participants reported their GP providing a Written asthma self-management plan, however rarely did participants voice that it was explained clearly or updated regularly. In terms of emotional support, most participants explained that doctors failed to be empathetic and demonstrate an understanding of their "sense of guilt", "anxiety", and the "constant worry" that their child's condition may be causing them. One of the key connections that participants then sourced were other health care professional connections (such as specialists), family, friends, and the Internet.

\section{Trust and Support}

Trustworthy and supportive connections were important in shaping participants' asthma networks. Participants reported pursuing management-related advice from those who have previously contributed to their child's asthma or had personal experiences of asthma themselves. Through positive interactions with both professional and social relationships, such as the provision of effective treatment options, quality information and successful recommendations founded a sense of "trust" and "support" in that connection. Connections that displayed effective communication (through active listening and displaying empathy), honesty, showed respect, and cared for participants and their children helped build trusting relationships. Trusted connections were described to have an important role in expanding participants' networks, which potentially improved their child's asthma medication management.

\section{The Need for More Information}

While participants continuously reported wanting more information relating to equipping them to be able to deliver "the best possible care for their child", their need for more information was driven by a complex multitude of factors and underlying issues.

Some participants wished for more information regarding management strategies, which would enable them to feel involved in the management of their child's illness, more confident, and be able to understand the decisions being made. They reported that feeling that they understood what was happening helped some participants to cope with their child's illness and re-establish a sense of control.

Others felt that information provided by their primary HCP was lacking. This was due to physical barriers, such as a lack of time, or that insufficient information had been provided. Immediately after a child's diagnosis of asthma, many participants reported that they experienced difficulties taking in the information that was presented to them and were left with "many questions" after consultations with HCPs. This was due to the large amount of information imparted, causing "information overload"; feeling "overwhelmed" as to the realization that their child has a chronic condition; and/or the use of medical jargon. In all of these instances, participants would turn to as many different individuals and resources as they could to answer their questions.

\section{Confidence in Management}

Participants who expressed that they did not have an active need to acquire further information from sources other than their HCPs were confident in dealing successfully with the ongoing management of their child's asthma medication. They were "satisfied" and "happy" with the resources and information they were receiving from their HCPs and felt that they 
could "manage all their medications and symptoms" on their own. These participants reported discussing their child's asthma with fewer people in comparison to others who did not display this same level of confidence.

\section{Perception of their Child's Asthma Severity}

The level of interaction and selection of individuals/resources within participant's asthma networks were also influenced by the participant's perceptions of their child's asthma severity. Participants who viewed their child's asthma to be mild in comparison to other children kept their asthma networks small, and rarely interacted with family and friends in regard to medication management of their child's asthma. In fact, they reported a desire to keep all interactions about their child's asthma to a minimum. They reported that they were "confident" to manage their child's condition on their own.

In contrast, participants who perceived their child's asthma to be "poorly controlled" actively sought both physical and emotional 'support' from people that were already known to them or formed new connections. In looking for support, they were actually looking for ways to increase their "confidence" across all aspects of asthma medication management. These parents sought out additional information from different sources, especially when their child was experiencing an asthma flareup. Consequently, these participants had larger asthma networks.

\section{Convenience}

When it came to seeking medication advice, participants made decisions about which individual or resource to utilize based on the level of convenience. The more convenient the source was, the more frequently participants reported to utilize and interact with it. The Internet was an easy and convenient source of medication information both prior to and after their interaction with HCPs, especially when HCPs lacked time during consultations, or participants wanted to re-affirm something that they had heard. By accessing asthma-related websites, participants were able to diagnose and treat symptoms promptly and timely if they were unsure what to do. When it came to HCPs, those who were easily accessible and could provide quick information and advice, such as the pharmacist, were utilized often when in need of reliable information or emergency medication. These HCPs were also held in high esteem in these situations, particularly hospital staff, as they were easily accessible to provide treatment in life-threatening situations.

\section{DISCUSSION}

This study explored the asthma networks of parents of children with asthma and has identified the role of individuals within their networks, how they influence the way in which they manage their children's asthma medications, and the factors driving their development. A qualitative exploration of the parents' network utilizing the principles of social network theory $[22,48]$ was employed in this study and has not been conducted previously in this cohort. Important outcomes of this study highlight that when it came to the management of their children's asthma medications, parents actively sought advice and support from a series of individuals with whom they had complex and multidimensional relationships; including HCPs, personal connections, lay individuals, and resources. Some individuals directly influenced asthma medication management decisions made by parents, others provided emotional or informational support for asthma management and some connections were unrelated to the child's asthma but instead provided physical support to the needs of parents. The development of these asthma networks occurred over time and was influenced by their satisfaction with their primary HCP provider; trust and the support provided; the need for different information; convenience; their own confidence in managing the condition; and parents' perceptions of their children's asthma severity.

The in-depth exploration of each connection in parents' asthma networks found that parents 
have a multitude of needs that are fulfilled by different individuals/resources. What parents perceived their children's asthma needed and who/what they felt was capable/available to fulfil these needs strongly influenced their selection of health connections. Support from family and friends was orientated to all aspects of the parents' everyday lives, while friends and family members who either had asthma or a child who did, shared their advice and experiences, filling in gaps in knowledge, helping parents in management decisions and ultimately playing a key influential role. The Internet, a convenient and easily accessed resource for health information, aided in asthma management decisions. Other relationships in parents' networks, such as schools, while not influential, were important to parents, and provided them with the physical support they needed. In contrast, HCPs focused on the diagnosis and treatment of the condition, providing professional advice for their children's asthma. Generally, parents saw GPs and specialists as gatekeepers to their children's asthma medications, truly influencing the asthma medicine management decisions made by parents. Specialists were highly respected and instilled a sense of confidence in parents that the medications prescribed, and management recommended is the most appropriate for their child. While pharmacists had the knowledge and skills to assist parents with asthma management, for most parents, they were relationships of convenience, where they simply supplied what the doctor had prescribed, having little influence on the parent's management decisions. This is not surprising, as other research has shown patients continue to prefer physician-led service [22, 36]. For those parents who were more engaged with the pharmacist, it was clear that their level/extent of influence was meaningful. They respected their advice and help and spoke highly of them. In trying to better support the needs of parents, perhaps we need to re-consider where the role of HCPs currently fits in and how we may evolve this role over time to meet all their needs. By exploring these connections, it has provided new information on which HCPs may act on to better engage and utilize patients' existing health connections so that they better meet parents' needs.

Parents' health connections were led by experiences of the condition, their experiences with their HCPs, and the child as they grew older and received more autonomy in the management of their asthma. Ultimately, a parent's relationship with their primary provider, such as their GP, played the biggest role in a parent's choices and selection of connections within their health networks. Despite their fundamental and influential role, their satisfaction with their primary provider, the trust they had in the relationship, if they had met parent's information needs, delivered uniformity in education in line with other HCPs and instilled in them a sense of confidence in managing their children's asthma, determined the extent they sought out other connections to meet their needs. Unfortunately, a large proportion of parents were disappointed with their primary providers. This disappointment in primary providers is mirrored in a study by Peterson-Sweeney et al., where parents voiced the lack of education they received from their GPs [37]. However, this study highlights that it has resulted in parents seeking out more health information and support from various individuals or resources to fill in this void and that it is affecting their willingness to communicate with their primary provider and as well as other HCPs. This is concerning, as other connections may not be equipped to provide good-quality professional advice and information. Ensuring these relationships are positive and that HCPs are meeting parents' needs is important. This can be achieved by focusing on the patient experience at every level to increase patient satisfaction, especially at first contact. Positive first interactions with parents as well as patients tend to strongly shape the experiences and emotions that follow, especially when children are first diagnosed at the hospital. Including the child and parent in a triadic discussion as part of a HCPs clinical approach helps foster a positive relationship [38]. When initial consultations with their HCP go well, a positive cycle begins with their HCP; when it goes poorly, as was the case with a large number of parents in this study, it may be difficult to recover. Negative 
relationships, poor experiences, and a lack of communication have been shown in adults to limit a professional's ability, or wiliness, to identify a patient's health beliefs; education needs; a patient's confidence in managing their own asthma; relevant, non-medical lifestyle factors impacting control; etc. [11, 38-42]. Only by identifying these patient factors through good communication, positive and trusting relations with both parents and children will HCPs be able to present more meaningful, targeted information for patients, which will, in turn, promote better asthma understanding and more effective self-care, and enable professionals to support asthma patients appropriately [38]. In short, the poverty of good professional communication, trust, and support leads to poor asthma management for parents of children with asthma and in turn, facilitates network expansion. Further, patients become a sum of all their experiences over time, and it is important that these experiences remain positive, so that they are better equipped to manage their asthma, leading to improved pediatric asthma outcomes.

This study highlights the important link between health and social relations in the management of children's asthma medications. When looking at the influence of social support on chronic illnesses such as asthma, they can be both positive and negative [48-53]. It is difficult to determine the quality and accuracy of advice and information that family and friends are providing parents. This is especially worrisome if parents are taking this advice on board over HCP advice. Health care professionals need to consider the influential impact family and friends have on parents. Management education should incorporate skills and strategies designed to minimize social influences that hinder the optimal management of their child's asthma and enhance social interactions that facilitate successful management [41, 43, 44]. Studies have shown that patient behavior is highly influenced by family members and friends, resulting in decreased risk of serious illness or death $[48,49]$. Adults have reported to turn to family members and friends prior to seeing an HCP or using the Internet to learn from the personal lived experiences of individuals who share similar conditions, especially through participation in online health communities [50, 51, 54, 55]. Through the provision of support and exchange of health information, social connections are proposed to promote healthy eating [52], provide emotional support to help adults with asthma to better cope with their condition [48], and motivate them to participate in preventive care programs [53]. Future research needs to reveal a deeper understanding of the social context in which this occurs in parents of children with asthma, which would allow for the development of tailored interventions that consider the specific roles of family and friends to maximize positive outcomes.

Given the complex needs of parents in the ongoing management of their children's asthma, such as symptom monitoring, medication adherence, lifestyle changes, and emotional stress, this study conveys that simply having one health connection alone was insufficient to provide all the support parents needed and required to address their needs. It is clear from our results that HCPs are no longer the sole source of input. HCP solely delivering health care may not be an accurate approach to health-care delivery and providers need to consider the influences of lay advice on parents. It highlights the need to develop pediatricspecific guidelines for asthma management that foster a 'community' approach to management and the need for uniformity in education required between all HCPs. With parents interacting just as frequently with family, friends, and the Internet compared to HCPs, there is much more work to be done to effectively engage parents with HCPs to ensure that they are receiving correct information and are properly supported to provide optimal care for their children's asthma. This is especially highlighted in the fact that all of the children in this study had been hospitalized at least once for their asthma, showing already the potential failure of the primary care system. Given the increasing demands on the time of primary care doctors, particularly in the area of chronic disease management, perhaps referrals to specialists need to be considered more often or a need for greater involvement of community pharmacists 
or nurses. It has been repeatedly shown throughout the literature that adults with asthma have benefited from pharmacists' interventions in their asthma care [57-60]. A study by Saini et al. [57] highlighted that pharmacists who deliver specialized models of asthma care to patients are also able to meet their needs. Policies need to enable other health professionals, such as pharmacists, to contribute to optimal chronic disease management if primary providers are not able to meet the demands. However, pediatric asthma is a chronic disease that is often under-represented and under-prioritized by policymakers, government bodies, healthcare professionals, and researchers.

While this study has added valuable insights to our understanding of the key influences in parents' management of their children's asthma medications, research limitations need to be considered. That is (i) this study was conducted in only one particular Australian district, (ii) all the parents interviewed were female, although the latest Census data show that fewer than one in 20 families have a father who is the primary carer [45], (iii) the vast majority of the participants had very mild asthma, with the majority symptom-free for the past month, (iv) although interview data were independently reviewed, interpretive bias should be considered. However, interpretation is never completely independent of a researcher's beliefs and preconceptions [46]. To minimize bias, regular meetings were held to critically compare and discuss findings. Further, these findings are based on a cross-sectional case study and parent relationships that may change over time and under different circumstances, leading to different asthma networks. A time series design study or an ethnographic study should be considered to examine parents' asthma networks at different time points during childhood in order to look at the development of these networks over time. This would allow us to gain further understanding of how these asthma networks came to evolve over time.

\section{CONCLUSIONS}

In conclusion, this study has uncovered the important and underestimated role of parents' non-medical sources of information/support. It also highlights the complex relationship between HCPs, parents' non-medical sources of information/support, and the intimate and parallel influence they have on a parent's decision-making when it comes to the management of their child's asthma medications. Simply, HCPs are not able to provide all the support parents need and require to address their needs when it comes to the management of their children's asthma medications. This study supports the need for a collaborative approach to the management of pediatric asthma, which involves both medical and non-medical individuals, uniformity in education between all individuals involved, and highlights the need to develop pediatric-specific guidelines for asthma management that foster a 'community' approach to management.

\section{ACKNOWLEDGEMENTS}

The authors would like to thank all the participants that volunteered to be part of this study.

Funding. No funding or sponsorship was received for this study or publication of this article.

Authorship. All named authors meet the International Committee of Medical Journal Editors (ICMJE) criteria for authorship for this article, take responsibility for the integrity of the work as a whole, and have given their approval for this version to be published.

Disclosures. Dr. Pamela Srour-Alphonse, Dr. Elizabeth Azzi, Dr. Lynn Cheong, Dr. Biljana Cvetkovski, and Prof. Cynthia S. Rand have nothing to disclose. Prof. Sinthia Bosnic-Anticevich is a member of the Teva Pharmaceuticals Devices International Key Experts Panel, has received research support from Research in Real Life, has received lecture fees and payment 
for developing educational presentations from Teva and Mundipharma; and has received honoraria from AstraZeneca, Boehringer Ingelheim, and GlaxoSmithKline for her contribution to advisory boards/key international expert forum. Dr. Vicky Kritikos has received honoraria from AstraZeneca, GlaxoSmithKline, and Pfizer.

Compliance with Ethics Guidelines. This project was approved by the University of Sydney Human Research Ethics Committee (Project No: 2015/762) and participants provided their informed consent to participate in the interviews.

Data Availability. The data are not publicly available as consent was not obtained from participants to share data outside of the requirements of the research process.

Open Access. This article is licensed under a Creative Commons Attribution-NonCommercial 4.0 International License, which permits any non-commercial use, sharing, adaptation, distribution and reproduction in any medium or format, as long as you give appropriate credit to the original author(s) and the source, provide a link to the Creative Commons licence, and indicate if changes were made. The images or other third party material in this article are included in the article's Creative Commons licence, unless indicated otherwise in a credit line to the material. If material is not included in the article's Creative Commons licence and your intended use is not permitted by statutory regulation or exceeds the permitted use, you will need to obtain permission directly from the copyright holder. To view a copy of this licence, visit http:// creativecommons.org/licenses/by-nc/4.0/.

\section{REFERENCES}

1. Statistics ABO. Asthma in Australia: A Snapshot 2004-05. Canberra: ABS; 2006.

2. ABoS. National health survey: first results, 2014-15. Canberra: ABS; 2016.
3. (Asthma) AIoHaW. The hidden cost of asthma. Australia: Astham Australia and National Asthma Council Australia; 2015.

4. Monitoring ACfA. Asthma in Australia 2011. Canberra: AIHW; 2011.

5. Marks G, Zinoviev A, Poulos L, Ampon R, Waters AM. Asthma in Australian children: findings from growing up in Australia, the longitudinal study of Australian children: Australian Government. Canberra: Australian Institute of Health and Welfare; 2009.

6. (AIHW) AIoHaW. The burden of chronic respiratory conditions in Australia: a detailed analysis of the Australian Burden of Disease Study 211. Canberra: AIHW; 2017.

7. Archibald MM, Caine V, Ali S, Hartling L, Scott SD. What is left unsaid: an interpretive description of the information needs of parents of children with asthma. Res Nurs Health. 2015;38(1):19-28.

8. Archibald MM, Scott SD. The information needs of North American parents of children with asthma: a state-of-the-science review of the literature. J Pediatr Health Care. 2014;28(1):5-13.e2.

9. Harrington KF, Zhang B, Magruder T, Bailey WC, Gerald LB. The impact of parent's health literacy on pediatric asthma outcomes. Pediatr Allergy Immunol Pulmonol. 2015;28(1):20-6.

10. DeWalt DA, Dilling MH, Rosenthal MS, Pignone MP. Low parental literacy is associated with worse asthma care measures in children. Ambul Pediatr. 2007;7(1):25-31.

11. Harrington KF, Haven KM, Bailey WC, Gerald LB. Provider Perceptions of Parent Health Literacy and Effect on Asthma Treatment Recommendations and Instructions. Pediatr Allergy Immunol Pulmonol. 2013;26(2):69-75.

12. Milgrom H, Bender B, Ackerson L, Bowry P, Smith B, Rand C. Noncompliance and treatment failure in children with asthma. J Allergy Clin Immunol. 1997;98:57.

13. Bender B, Zhang L. Negative affect, medication adherence, and asthma control in children. J Allergy Clin Immunol. 2008;122(3):490-5.

14. Rand CS. Adherence to asthma therapy in the preschool child. Allergy. 2002;57(s74):48-57.

15. Aziz NA, Norzila M, Hamid M, Noorlaili M. Skills amongst parents of children with asthma: a pilot interventional study in primary care setting. Med J Malaysia. 2006;61(5):534-9. 
16. Burkhart PV, Rayens MK, Bowman RK. An evaluation of children's metered-dose inhaler technique for asthma medications. Nurs Clin. 2005;40(1): 167-82.

17. Gillette C, Rockich-Winston N, Kuhn JA, Flesher S, Shepherd M. Inhaler technique in children with asthma: a systematic review. Acad Pediatr. 2016;16(7):605-15.

18. Srour-Alphonse P, Cvetkovski B, Rand CS, Azzi E, Tan R, Kritikos V, et al. It takes a village-asthma networks utilized by parents when managing childhood asthma medications. J Asthma. 2019;2: $1-13$.

19. Rosier MJ, Bishop J, Nolan T, Robertson CF, Carlin JB, Phelan PD. Measurement of functional severity of asthma in children. Am J Respir Crit Care Med. 1994;149(6):1434-41.

20. Cheong LH, Armour CL, Bosnic-Anticevich SZ. Multidisciplinary collaboration in primary care: through the eyes of patients. Austr J Primary Health. 2013;19(3):190-7.

21. Cheong LH, Armour CL, Bosnic-Anticevich SZ. Patient asthma networks: understanding who is important and why. Health Exp Internat J Pub Care Health Policy. 2015;18(6):2595-605.

22. Cheong LHM, Armour CL, Bosnic-Anticevich SZ. Primary health care teams and the patient perspective: a social network analysis. Res Soc Admin Pharma. 2013;9(6):741-57.

23. Australia NAC. Australian Asthma Handbook. Melbourne: National Asthma Council Australia; 2017.

24. Beacham BL, Deatrick JA. Health care autonomy in children with chronic conditions: implications for self-care and family management. Nurs Clin North Am. 2013;48(2):305-17.

25. Karlsson A, Arman M, Wikblad K. Teenagers with type 1 diabetes-a phenomenological study of the transition towards autonomy in self-management. Int J Nurs Stud. 2008;45(4):562-70.

26. Smetana JG, Campione-Barr N, Daddis C. Longitudinal development of family decision making: defining healthy behavioral autonomy for middleclass African American adolescents. Child Dev. 2004;75(5):1418-34.

27. Wray-Lake L, Crouter AC, McHale SM. Developmental patterns in decision-making autonomy across middle childhood and adolescence: European American parents' perspectives. Child Dev. 2010;81(2):636-51.
28. Self-management approaches for people with chronic conditions- a review.

29. Barlow J, Wright C, Sheasby J, Turner A, Hainsworth J (2002) Self-management approaches for people with chronic conditions: A review.

30. Brown JV, Avery E, Mobley C, Boccuti L, Golbach T. Asthma management by preschool children and their families: a developmental framework. J Asthma. 1996;33(5):299-311.

31. Brown N, Gallagher R, Fowler C, Wales S. Asthma management self-efficacy in parents of primary school-age children. J Child Health Care. 2014;18(2):133-44.

32. Bursch B, Schwankovsky L, Gilbert J, Zeiger R. Construction and validation of four childhood asthma self-management scales: parent barriers, child and parent self-efficacy, and parent belief in treatment efficacy. J Asthma. 1999;36(1):115-28.

33. Butz AM, Walker JM, Pulsifer M, Winkelstein M. Shared decision making in school age children with asthma. Pediatr Nurs. 2007;33(2):111-6.

34. Horne R, Weinman J. Self-regulation and selfmanagement in asthma: exploring the role of illness perceptions and treatment beliefs in explaining non-adherence to preventer medication. Psychol Health. 2002;17(1):17-32.

35. Pradel FG, Hartzema AG, Bush PJ. Asthma selfmanagement: the perspective of children. Patient Educ Couns. 2001;45(3):199-209.

36. Tinelli M, Bond C, Blenkinsopp A, Jaffray M, Watson M, Hannaford P. Patient evaluation of a community pharmacy medications management service. Ann Pharmacother. 2007;41(12):1962-70.

37. Peterson-Sweeney K, McMullen A, Yoos HL, Kitzman H. Parental perceptions of their child's asthma: management and medication use. J Pediatr Health Care. 2009;17(3):118-25.

38. Moffat M, Cleland J, van der Molen T, Price D. Poor communication may impair optimal asthma care: a qualitative study. Fam Pract. 2007;24(1):65-70.

39. Sleath B, Carpenter DM, Slota C, Williams D, Tudor $\mathrm{G}$, Yeatts $\mathrm{K}$, et al. Communication during pediatric asthma visits and self-reported asthma medication adherence. Pediatrics. 2012;130(4):627-33.

40. Tates K, Meeuwesen L. Doctor-parent-child communication. A review of the literature. Soc Sci Med. 2001;52(6):839-51.

41. Wassmer E, Minnaar G, Abdel Aal N, Atkinson M, Gupta E, Yuen S, et al. How do paediatricians 
communicate with children and parents? Acta Paediatr. 2004;93(11):1501-6.

42. Wilson SR, Strub P, Buist AS, Knowles SB, Lavori PW, Lapidus J, et al. Shared treatment decision making improves adherence and outcomes in poorly controlled asthma. Am J Respir Crit Care Med. 2010;181(6):566-77.

43. Rhee H, Belyea MJ, Brasch J. Family support and asthma outcomes in adolescents: barriers to adherence as a mediator. J Adolesc Health Off Pub Soc Adolesc Med. 2010;47(5):472-8.

44. Clark N, Gong M, Schork M, Kaciroti N, Evans D, Roloff $\mathrm{D}$, et al. Long-term effects of asthma education for physicians on patient satisfaction and use of health services. Eur Respir J. 2000;16(1):15-21.

45. ABS. National Health Survey: First Results, 2014-15. Canberra: ABS; 2016.

46. Kaptchuk TJ. Effect of interpretive bias on research evidence. BMJ. 2003;326(7404):1453-5.

47. Bernard HR. Research methods in anthropology. Lanham: AltaMira Press; 2011.

48. Reeves D, Blickem C, Vassilev I, Brooks H, Kennedy A, Richardson $G$, et al. The contribution of social networks to the health and self-management of patients with long-term conditions: a longitudinal study. PLOS ONE. 2014;9:98340.

49. Tucker J. Health-related social control within older adults' relationships. J Gerontol Psychol Sci Soc. 2002;57:387-95.

50. Gallant M. The influence of social support on chronic illness self-management: a review and directions for research. Health Educ Behav. 2003;30:170-95.

51. Kyngas H. Support network of adolescents with chronic disease: adolescents' perspective. Nurs Health Sci. 2004;6:287-93.

52. Scholz U, Oschsner S, Rainer H, Knoll N. Does social support really help to eat a low-fat diet? Main effects and gender differences of received social support within the health action process approach. Appl Psychol Health Well-being. 2013;5:270-90.
53. Cram P, Fendrick A, Inadomi J, Cowen M, Carpenter D, Vijan S. The impact of a celebrity promotional campaign on the use of colon cancer screening: the Katie Couric effect. Arch Internal Med. 2003;163:1601-5.

54. De Simoni A, Shah AT, Fulton O, Parkinson J, Sheikh A, Panzarasa P, et al. Superusers' engagement in asthma online communities: asynchronous web-based interview study. J Med Internet Res. 2020;22(6):e18185.

55. Joglekar S, Sastry N, Coulson NS, Taylor SJ, Patel A, Duschinsky R, et al. How online communities of people with long-term conditions function and evolve: network analysis of the structure and dynamics of the asthma UK and British lung foundation online communities. J Med Internet Res. 2018;20(7):e238.

56. Tong A, Sainsbury P, Craig J. Consolidated criteria for reporting qualitative research (COREQ): a 32-item checklist for interviews and focus groups. Int J Qual Health Care. 2007;19:349-57.

57. Saini B, Krass I, Smith L, Bosnic-Anticevich S, Armour C. Role of community pharmacists in asthma - Australian research highlighting pathways for future primary care models. Austr Med J. 2011;4(4):190-200.

58. Emmerton LM, Smith L, LeMay KS, et al. Experiences of community pharmacists involved in the delivery of a specialist asthma service in Australia. BMC Health Serv Res. 2012;12:164.

59. Deeks LS, Kosari S, Boom K, Peterson GM, Maina A, Sharma R, Naunton M. The role of pharmacists in general practice in asthma management: a pilot study. Pharmacy (Basel, Switzerland). 2018;6(4): 114.

60. Bridgeman MB, Wilken LA. Essential role of pharmacists in asthma care and management. J Pharm Practice. 2020;2:10.

61. Dowell J, Arcoleo K, Ruiz Z, Halula R. Children with asthma and communication with healthcare provider: instrument development. J Pediatr Nurs. 2020;50:81-8 